\title{
A stranger in the heart
}

\section{P. 274}

\section{Correct answer D}

Primary cardiac tumors are extremely rare and are mainly benign in nature. Myxomas are the most common benign cardiac tumors typically affecting middle-aged women. They can occur in either atrium but are most commonly attached to the fossa ovalis of the left atrium. Cardiac lipomas are other benign tumors and can occur in any age group but are most prevalent between the ages 40 and 60 years. The most common location of cardiac lipomas is the subendocardial region, with a particular predilection for the right atrium and the left ventricle (1).

Primary cardiac sarcomas are also extremely rare, and even if they are completely excised, their prognosis is overall very poor (2). These tumors account for only $10 \%-20 \%$ of all primary cardiac neoplasms and can be further subdivided according to histological features. Left heart sarcomas are broad based and are abnormally located, which differentiates them from myxomas, and they commonly present with dyspnea on exertion owing to congestive heart failure because their mass effect obstructs blood flow. Rhabdomyosarcoma has a predilection for the ventricle, and most cases of it appear in children at a mean age of approximately 14 years. Intimal pleomorphic sarcomas have a female predominance with a mean presenting age of 47 years and involve the posterior wall of the left atrium in $>80 \%$ of reported cases (3).

In our patient, pathological examination revealed that the mass was undifferentiated pleomorphic intimal sarcoma with MDM2 amplification. Owing to the invasive nature of this neoplasm, the patient was referred to the oncology department. One month later, control transthoracic echocardiography was normal (Video 6). In addition to its histological features, age and tumor localization were more consistent with the features of pleomorphic intimal sarcoma than with those of other sarcomas, such as rhabdomyosarcoma. Because $>90 \%$ of cardiac thrombus originate from the left atrial appendage and coupled with its echocardiographic appearance, the mass was not suggestive of cardiac thrombus.

Informed consent: Written informed consent for publication of her clinical details and clinical images was obtained from the patient.
Video 1. Apical four-chamber view on transthoracic echocardiography showing a giant mass in the left atrium, which is prolapsing to the left ventricle during diastole

Video 2. A long-axis view (135 degrees) on transesophageal echocardiography showing the giant mass restricting diastolic flow

Video 3. Four-chamber view (0 degrees) on transesophageal echocardiography showing a giant mass in a storiform pattern, occupying the left atrium almost completely and prolapsing to the left ventricle

Video 4. A three-dimensional transesophageal echocardiographic appearance of the mass

Video 5. Bicommissural view (60 degrees) on transesophageal echocardiography showing the mass. Neither thrombus nor spontaneous echocardiographic contrast is seen in the left atrium and appendage

Video 6. Parasternal long-axis view on transthoracic echocardiography one month after excision showing no residual mass in the left atrium

Uğur Nadir Karakulak* (D), Sinem Kılıç* (D), Banu Evranos* (D), Ahmet Aydın** (D), Mustafa Yılmaz** (iD

Departments of *Cardiology, and **Cardiovascular Surgery,

Faculty of Medicine, Hacettepe University; Ankara-Turkey

\section{References}

1. D'Souza J, Shah R, Abbass A, Burt JR, Goud A, Dahagam C. Invasive Cardiac Lipoma: a case report and review of literature. BMC Cardiovasc Disord 2017; 17: 28. [Crossref]

2. Alam L, Agrawal K, Kankanala V, Fishberg R, Powell D. Primary Cardiac Undifferentiated High-Grade Intimal Pleomorphic Sarcoma: A Case Series Report. Cardiol Res 2020; 11: 129-33. [Crossref]

3. Maleszewski JJ, Bois MC, Bois JP, Young PM, Stulak JM, Klarich KW. Neoplasia and the Heart: Pathological Review of Effects With Clinical and Radiological Correlation. J Am Coll Cardiol 2018; 72: 202-27. [Crossref]

Address for Correspondence: Dr. Uğur Nadir Karakulak, Hacettepe Üniversitesi Tıp Fakültesi, Kardiyoloji Anabilim Dalı, Sıhhiye 06170, Ankara-Türkiye Phone: +903123051780 +903123100580 (fax) E-mail: ukarakulak@gmail.com

Accepted Date: 14.01.2021 Available Online Date: 17.03.2021 